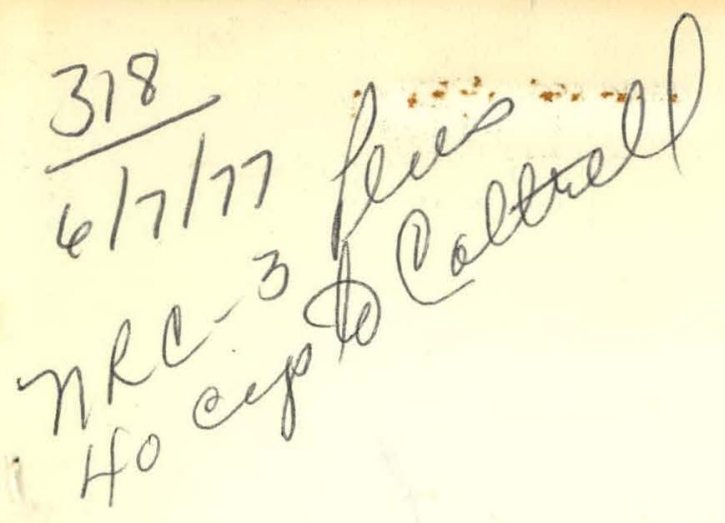

\title{
FACTORS THAT AFFECT THE CALIBRATION OF TURBINES IN SINGLE-PHASE FLOW
}

\author{
THOMAS C. PIPER
}

May 1977

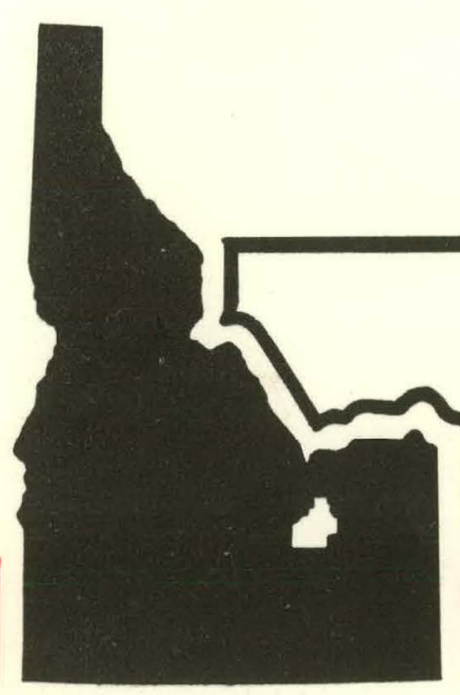

EG\&G Idaho, Inc.
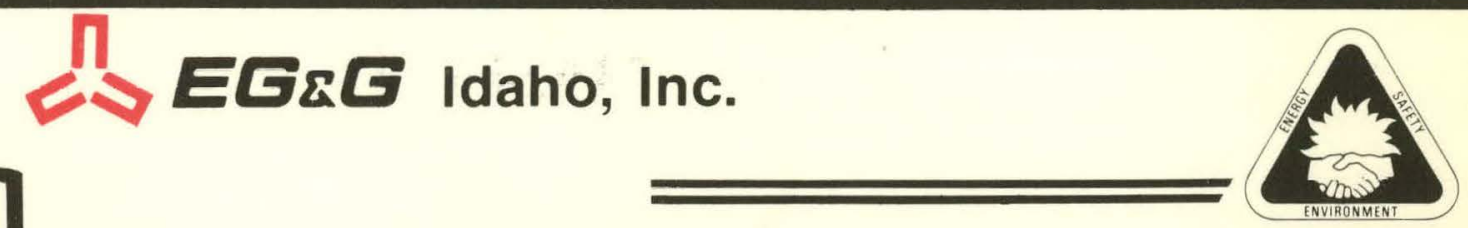

IDAHO NATIONAL ENGINEERING LABORATORY

\section{ENERGY RESEARCH AND DEVFLOPMENT ADMINISTRATION}




\section{DISCLAIMER}

This report was prepared as an account of work sponsored by an agency of the United States Government. Neither the United States Government nor any agency Thereof, nor any of their employees, makes any warranty, express or implied, or assumes any legal liability or responsibility for the accuracy, completeness, or usefulness of any information, apparatus, product, or process disclosed, or represents that its use would not infringe privately owned rights. Reference herein to any specific commercial product, process, or service by trade name, trademark, manufacturer, or otherwise does not necessarily constitute or imply its endorsement, recommendation, or favoring by the United States Government or any agency thereof. The views and opinions of authors expressed herein do not necessarily state or reflect those of the United States Government or any agency thereof. 


\section{DISCLAIMER}

Portions of this document may be illegible in electronic image products. Images are produced from the best available original document. 
Printed in the Uniled States of America Available from

National Technical Information Service

U.S. Department of Commerce

5285 Port Royal Road

Springfield, Virginia 22161

Price: Printed Copy $\$ 4.00$; Microfiche $\$ 3.00$

"The NRC will make available data tapes and operational computer codes on research programs dealing with postulated loss-of-coolant accidents in light water reactors. Persons requesting this information must reimburse the NRC contractors for their expenses in preparing copies of the data tapes and the operational computer codes. Requests should be submitted to the Research Applications Branch, Office of Nuclear Regulatory Research, Nuclear Regulatory Commission, Washington, D.C. 20555."

\section{NOTICE}

This report was prepared as an account of work sponsored by the United States Government. Neither the United States nor the Energy Research and Development Administration, nor the Nuclear Regulatory Commission, nor any of their employees, nor any of their contractors, subcontractors, or their employees, makes any warranty, express or implied, or assumes any legal liability or responsibility for the accuracy, completeness or usefulness of any information, apparatus, product or process disclosed, or represents that its use would not infringe privately owned rights. 
TREE-NUREG-1082

(ANCR-NUREG-1350)

\section{FACTORS THAT AFFECT THE CALIBRATION OF TURBINES IN SINGLE-PHASE FLOW}

Approved:
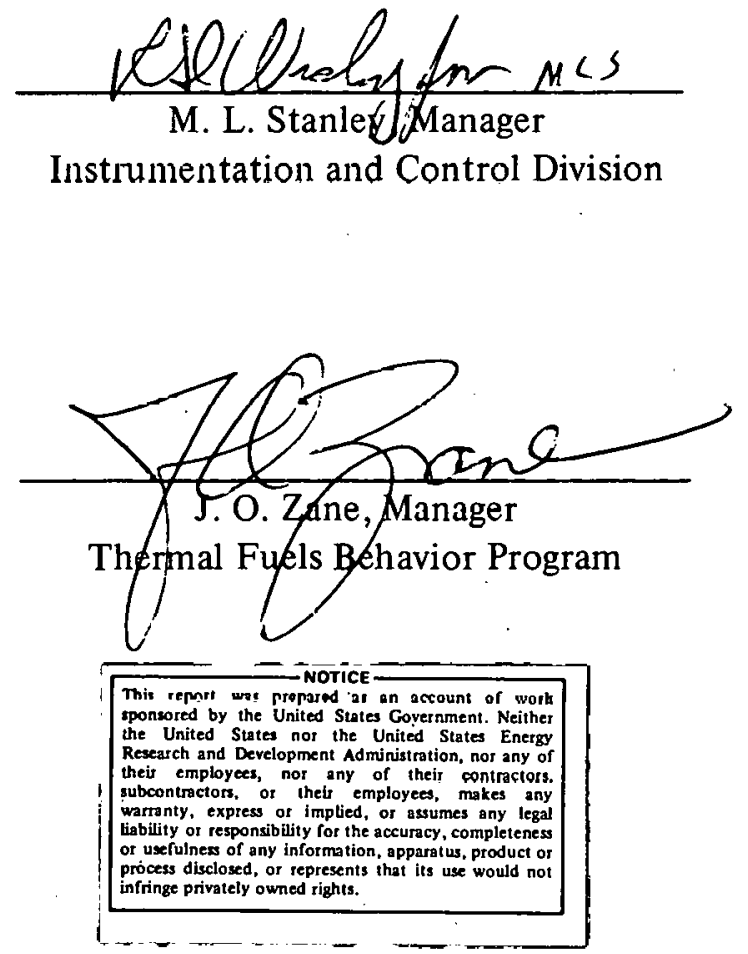


\title{
FACTORS THA'I AFHELI THE CALIBRATION OF TURBINES IN SINGLE-PHASE FLOW
}

\author{
by \\ Thomas C. Piper \\ EG\&G IDAHO, INC.
}

May 1977

PREPARED FOR THE

U.S. NUCLEAR REGULATORY COMMISSION AND

ENERGY RESEARCH AND DEVELOPMENT ADMINISTRATION IDAHO OPERATIONS OFFICE UNDER CONTRACT NO. EY-76-C-07-1570 


\section{ACKNUWLEDGMENTS}

The author wishes to thank those who have contributed to the support and completion of this work: Dr. Van Houten of the Nuclear Regulatory Commission for his interest and for requesting the present work, R. W. Miller and the Thermal Fuels Behavior Program for the financial support of the work, and R. H. Meservey of Instrumentation and Control for his understanding and help during manuscript preparation. 


\begin{abstract}
Basic turbine operation in single-phase flow is related. Causes and relative magnitudes of retarding torque are given for two sizes of turbines when used for water flow measurement. An equation for slip caused by retarding torques is given. Evaluation of turbine slip behavior at the turbine low flow region shows that bearing retarding torques, change in flow patterns, or other effects can predominate in the relatively large changes in " the calibration "constant" that occur there. Fluid lubricity is singled out as an important fluid property in certain types of bearings and flow. Temperature induced changes in turbine size are shown to cause calibration changes if a turbine is used at a temperature significantly different than that at which it was calibrated.
\end{abstract}

This report was previously referenced as ANCR-NUREG-1350. 


\section{CONTENTS}

ACKNOWLEDGMENTS ....................... . . . . . . . .

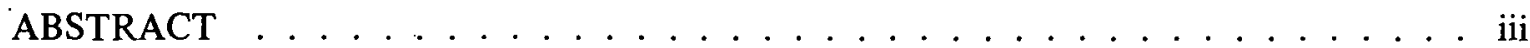

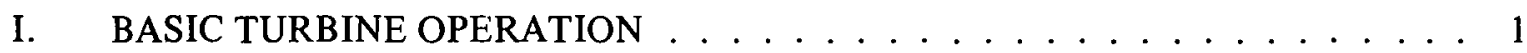

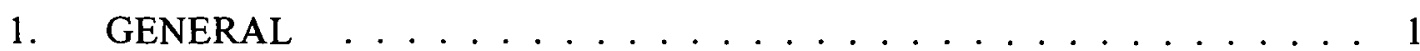

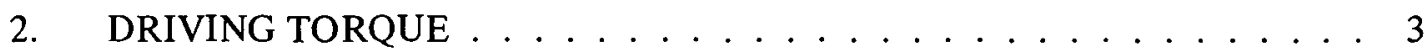

3. CALIBKAIIUN LUNSI'ANI WIIH NU KËIAKDING IUKUUES . . . . 4

4. FLUID RETARDING TORQUES ................ 5

4.1 Blade, Skin-Friction Retarding Torque ............ 5

4.2 Blade Tip Retarding Torque . . . . . . . . . . . . . . . . 6

4.3 Bearing Viscosity Retarding Torque ............. 7

5. CALIBRATION WITH FLUID RETARDING TORQUES . . . . . . . 8

6. FLUID LUBRICITY . . . . . . . . . . . . . . . 13

II. CHANGE IN CALIBRATION DUE TO TEMPERATURE . . . . . . . . . . . 14

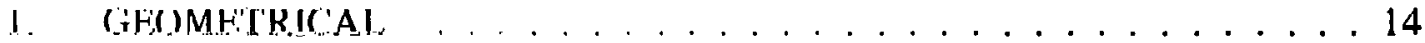

2. FLUID PROPERTIES ...................... 16

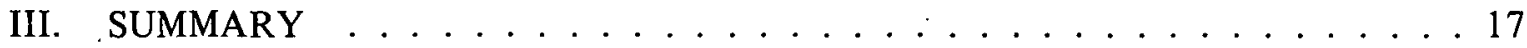

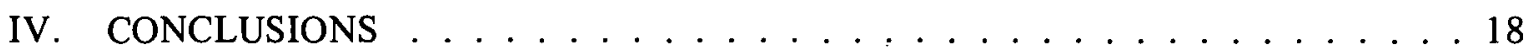

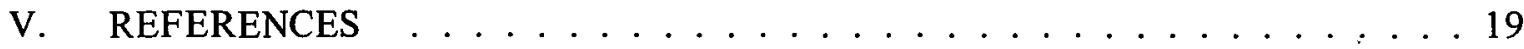

\section{FIGURES}

1. Views of rotor to illustrate slip ..................

2. Calibration constant for 2 to 20 gpm graphite turbines ........... 11

3. Calibration constant for 2 to $20 \mathrm{gpm}$ ball bearing turbine .......... 12

4. Calibration constant for 1 to $13 \mathrm{gpm}$ graphite turbines ........... 12 


\section{FACTORS THAT AFFECT THE CALIBRATION OF TURBINES IN SINGLE-PHASE FLOW}

\section{BASIC TURBINE OPERATION}

\section{GENERAL}

A turbine operating as a volumetric flow rate measurement device consists of a rotor free wheeling inside a tubular enclosure. Passage of liquid around the rotor causes it to turn at a rate closely proportional to the volumetric flow rate occurring. The rotor angular velocity is normally determined by a "magnetic pickup" detecting passage of rotor blades via the alteration of the magnetic field at the pickup coil. This occurs as each blade comes near the pickup. Constancy of the pulses/gal output to $\pm 0.5 \%$ versus a 75 to 1 range of volumetric flow rate is perhaps an upper limit of what can be achieved ${ }^{[1]}$. Most turbines are operated over only about a 10 or 15 to 1 range. The usefulness of the turbine is limited at low flow rate by a change in flow profile from turbulent to laminar ${ }^{[1]}$.

The principle of operation is simple. Flow passing by the rotor causes it to rotate. Bearing friction and fluid viscosity tend to retard the rotor rotational rate from being in strict synchronization with fluid flow (i.e., some rotor slip occurs). With slip occurring, the rotor is supplied a driving torque by imparting swirl to the fluid as it passes the blades. Figure 1 serves to illustrate the principles just discussed. All radii of a rotor blade cause some fluid swirl when rotor slippage is occurring.

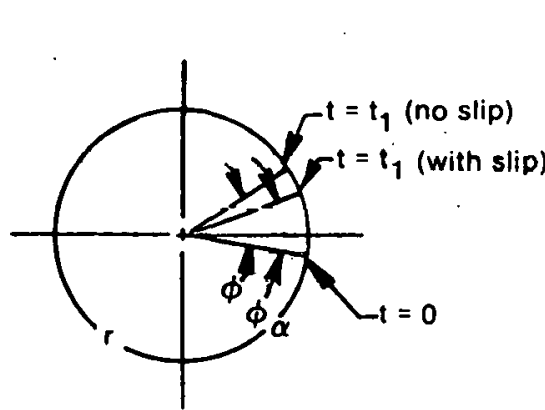

(a)

View of One Rotor Blade as Seen from Rotor Axis at Two Slightly Separated Time Intervals, With and Without Slippage.

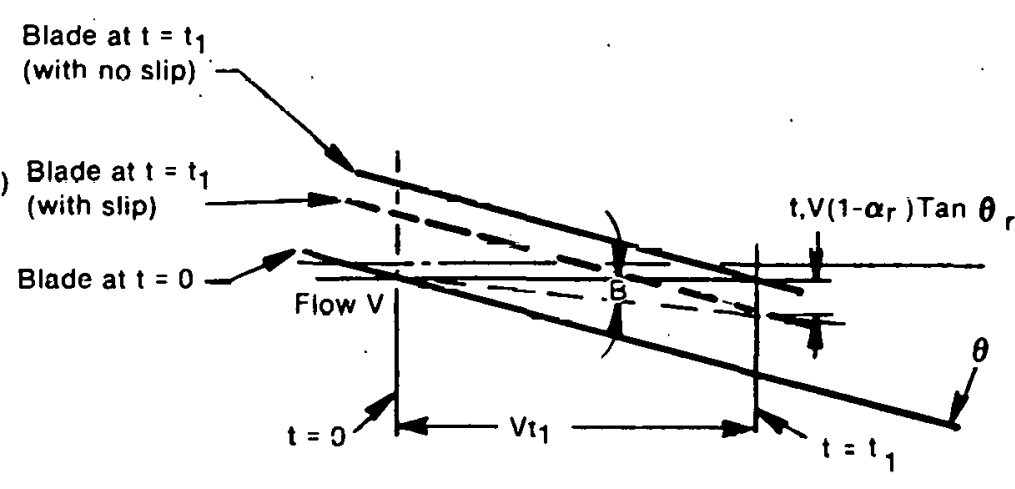

(b)

View of Same Rotor Blade at Radius $r$, Normal to Flow Axis at Two Slightly Separated Time Intervals. With and Without Slippage.

Fig. 1 Views of rotor to illustrate slip. 
The first few of the following definitions will help to clarify Figure 1:

$\theta_{\mathrm{r}}=$ rotor blade angle in radians with respect to the turbine rotational axis at radius $r$.

$\phi \quad=\quad$ angle in radians that rotor would turn in time $t_{1}$ if no rotor slip occurred.

$\dot{\phi}=$ rotor angular velocity in radians/sec.

$\alpha=\quad$ rotor nonslip factor, $\alpha_{\mathrm{r}}=\mathrm{r} \dot{\phi} / \mathrm{V}(\mathrm{r}) \tan \theta_{\mathrm{r}}$.

$\phi_{\alpha}=$ angle in radians that rotor turns in time $t_{1}$ with rotor slip $1-\alpha$.

$V(r) \equiv \quad$ fluid velocity at radius $r$ just in fiont of rotor blades.

$\mathrm{V}_{\mathrm{O}}=$ mean fluid velocity at radius $\mathrm{r}$ in rotor region.

$\mathrm{W}$. = blade width perpendicular to rotor rotational axis (in feet), assumed constant versus radius.

$\mathrm{h}=$ rotor hub radius in feet.

$r_{t}=$ rotor blade tip radius in feet.

l _ - rotor blåde thickness in feet.

B = turbine bore radius in feel.

$\rho=\quad=\quad$ fluid density in slug $/ \mathrm{ft}^{3}$ or $\mathrm{lb} \mathrm{sec}{ }^{2} / \mathrm{ft}^{4}$.

$\mu=$ fluid absolute viscosity in $\mathrm{lb} \mathrm{sec} / \mathrm{ft}^{2}$.

$y=\quad$ Cluid kinematic viscosity $(\mu / \rho) \mathrm{nn}^{2} /$ sec.

$\therefore \ldots e \quad$ fluid Reynolds number.

$\mathrm{b}=$ radius at which $a=1$, i.e., $\dot{\phi}=\frac{V(b) \tan \dot{\theta}_{\mathrm{b}}}{\mathrm{b}}$.

$\mathrm{N} \quad=\quad \because$ number of blades on turbine rotor.

$\mathrm{T}_{\mathrm{d}}=$ driving torque.

$\mathrm{T}_{\mathrm{v}}=$ retarding torque (viscous). 
A $=$ annular flow cross-sectional area at turbine rotor.

$\mathrm{C}_{\mathrm{O}}=$ turbine flow constant in $\frac{\text { radian }}{\mathrm{sec}} / \frac{\text { volume flow }}{\mathrm{sec}}$, or in pulses/gal.

The fluid deflection angle due to rotor slip is determined by noting from Figure 1 that

$$
\begin{aligned}
& \emptyset=\dot{\emptyset} t_{1}=\frac{v t_{1}}{r} \tan \theta_{r} \quad \text { for } \alpha=1 \\
& \emptyset_{\alpha}=\dot{\emptyset}_{\alpha} t_{1}=\frac{v t_{1}}{r} \alpha_{r} \tan \theta_{r} \quad \text { for } \alpha \neq 1
\end{aligned}
$$

or

$$
r\left(\emptyset-\emptyset_{\alpha}\right)=t_{1} v\left(1-\alpha_{r}\right) \tan \theta_{r}
$$

This distance, $t_{1} V\left(1-\alpha_{r}\right) \tan \theta_{r}$, is noted in its appropriate location in Figure 1. The triangle defined by $\mathrm{t}_{1} \mathrm{~V}\left(1-\alpha_{\mathrm{r}}\right) \tan \theta_{\mathrm{r}}, \mathrm{Vt}_{\mathrm{i}}$, and the hypotenuse lead to the deflection angle $\beta$ being.

$$
\beta_{r}=\arctan \left[\left(1-\alpha_{r}\right) \tan \theta_{r}\right]
$$

The fluid velocity perpendicular to the rotor axis is then

$$
V(r) \tan \beta_{r}=V(r)\left(1-\alpha_{r}\right) \tan \theta_{r} \text {. }
$$

\section{DRIVING TORQUE}

Assuming that only the fluid contacting the blade is deflected (i.e., a strip of width $W$ ), the driving torque imparted to the rotor per incremental blade length, $d r$, is

$$
d T_{r}=r \rho W V(r)\left[V(r)\left(1-\alpha_{r}\right) \tan \theta_{r}\right] d r
$$

or, the total driving torque due to rotor slippagc $\left(1-\alpha_{\mathrm{T}}\right)$ is

$$
T_{d}=N \rho W \int_{h}^{r} v^{2}(r) r\left(1-\alpha_{r}\right) \tan \theta_{p} d r .
$$

Assuming a constant rotor blade pitch:

$$
\frac{r}{\tan \theta_{r}}=\frac{b}{\tan \theta_{b}}=\text { constant }
$$


then

$$
T_{d}=\frac{N \rho W}{b} \tan \theta_{b} \int_{h}^{r} v^{2}(r) r^{2}\left(1-\alpha_{r}\right) d r
$$

Since the blade angle is assumed to vary as $\theta_{r \mathrm{r}}=\arctan \left(\frac{\mathrm{r}}{\mathrm{b}} \tan \theta_{\mathrm{b}}\right)$

$$
a_{r}=r \dot{\phi} /\left[v(r) \tan \theta_{r}\right]=b \dot{\emptyset}_{b} /\left[v(r) \tan \theta_{b}\right] \text {. }
$$

Now, because $V(r)$ is not normally a constant vcrsus radius, $\alpha_{r}$ will vary from somewhat less than unity to somewhat greater than unity, unless there are quite large frictional terms causing $\alpha_{\mathrm{r}}$ to be less than unity at all radii. Using Equation (8) in Equation (7):

$$
T_{d}=\frac{N \rho W}{b} \tan \theta_{b} \int_{h}^{r} v^{2}(r) r^{2}\left[1-\frac{b \dot{\phi}}{V(r) \tan \phi_{b}}\right] d r .
$$

\section{CALIBRATION CONSTANT WITH NO RETARDING TORQUES}

Reference 2 states the retarding torques to be small. It is thus interesting to inspect Equation (9) to see what happens when $T_{d}$ is set to zero. Writing Equation (9) with $T_{d}=0$ gives

$$
\int_{h}^{r} v^{2}(r) r^{2} d r=\frac{b \dot{\emptyset}}{\tan \theta_{b}} \int_{h}^{r} v(r) r^{2} d r .
$$

Or:

$$
\dot{\phi}_{\substack{\text { no } \\ \text { retarding } \\ \text { torque }}}=\dot{q}_{0}=\frac{\tan _{b}}{b} \frac{\int_{h}^{r t} \cdot v^{2}(r) r^{2} d r}{\int_{h}^{r} v(r) r^{2} d r} .
$$

Since any velocity profile, $V(r)$, can be written in terms of an infinite series:

$$
V(r)=V_{0}\left[1+\sum_{n=1}^{\infty} A_{n}\left(\frac{r}{R}\right)^{n}+\sum_{n=1} B_{n}\left(\frac{r}{R}\right)^{-n}\right]
$$




$$
\begin{aligned}
& \int_{h}^{r} t v^{2}(r) r^{2} d r=v_{0}^{2} f\left(h, r_{t}, R, A_{n}, B_{n}, . . . .\right)=v_{0}^{2} K_{1} \\
& \int_{h}^{r t} v(r) r^{2} d r=v_{0} g\left(h, r_{t}, R, A_{n}, B_{n}, . . .\right)=v_{0} K_{2} .
\end{aligned}
$$

So:

$$
\dot{\emptyset}_{0}=\frac{\tan \theta_{b}}{b} \cdot \frac{k_{1}}{k_{2}} v_{0}=k_{3} v_{0}
$$

and it can be concluded that with zero retarding torques, a constant velocity profile of any shape gives a turbine output linearly proportional to the flow rate. As a note of caution, the turbine calibration constant in pulses/sec/gal/sec is proportional to $\dot{\phi} / \mathrm{A} \mathrm{V}$ o where $\mathrm{A}$ is the turbine annular flow area at the rotor. Temperature or pressure can change the annular area and thus also the calibration constant. This will be discussed more in Section II-1.

\section{FLUID RETARDING TORQUES}

\subsection{Blade, Skin-Friction Retarding Torque}

Because fluid on the surfaces of the blade slides in a viscous boundary layer at an angle $\theta_{\mathrm{r}}$ with respect to the turbine axis, a reverse torque component results. Per incremental blade length, $\mathrm{dr}$, this torque is

$$
d T_{V}=-r C_{D} \frac{\rho V^{2}(r)}{2} 2 \frac{w \sin \theta}{\sin \theta_{r}} d r
$$

or

$$
T_{v} \cong-C_{D} N \rho W \int_{h}^{r} v^{2}(r) r d r
$$

where $\mathrm{W} / \sin \theta_{\mathrm{r}}$ is the actual blade width at radius $\mathrm{r}$ if the width perpendicular to the flow axis is assumed constant equal to $W$. Since drag occurs on each side of a blade, a factor of two has been included. Note that since drag under turbulent conditions cannot be handled other than by empirical relationships (in contrast to the drive term which can be calculated

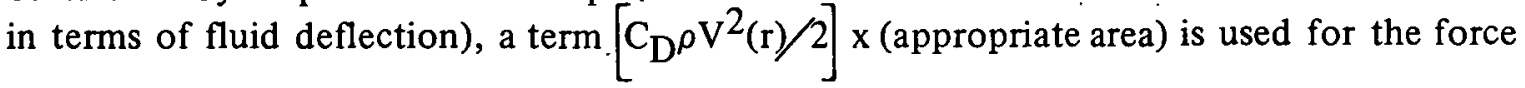


imparted to the blade parallel to its surface. $C_{D}$ is a function of Reynolds number, which in turn requires selection of a characteristic geometrical length. Various authors $[3,4]$ give different forms for $C_{D}$. For convenience, the present author uses the form given in Reference 3:

$$
C_{D}=0.079 /(\operatorname{Re})^{0.25} \text { with } \operatorname{Re}=\frac{\rho V_{0}(B-h)}{\mu} \text {. }
$$

Using this in Equation (17) gives

$$
T_{i v}=-\frac{0.079}{(R e)^{0.25}} \frac{N \rho}{R_{h}} \int^{t} v^{2}(r) r d r .
$$

Assuming $V(r)=V_{0}$ and performing the integral

$$
T_{v}=-\frac{\dot{U} \text { U7y NoW } v_{0}^{2}}{(\operatorname{Re})^{0.25}} \cdot \frac{r_{t}^{2}-h^{2}}{2} .
$$

\subsection{Blade Tip Retarding Torque.}

Reference 2 considers the proximity of the rotor blade tips to the inside bore of the turbine housing to be a source of drag (retarding torque). The purpose of the present section is to place the magnitude of this tip retarding torque in perspective with respect to that of the blade skin-friction retarding torque as estimated roughly in Equation (20).

$$
T_{t i p}=-c_{D} \frac{p U^{2}}{2} r_{t} \frac{w}{\sin \theta} t
$$

Again, $C_{D}=0.079 /(R e)^{0.25}$ is used, but $R e=r_{t} \dot{\phi}\left(B-r_{t}\right) / \mu$ and $U=r_{t} \dot{\phi}$.

Since $\dot{\phi} \approx \mathrm{V}_{\mathrm{o}} \tan \theta_{\mathrm{b}} / \mathrm{b}$ :

$$
T_{\text {tip }}=-\frac{0.079 \mathrm{~N}_{\rho} W v_{0}{ }^{\frac{r_{t}^{3}}{b^{2}}} \iota \operatorname{ldn}^{2} \theta_{b}}{2\left[\rho \frac{r_{t}\left(B-r_{t}\right) v_{0} \tan \theta_{b}}{\mu b}\right]^{0.25} \sin \theta_{t}}
$$


This can also be written as

$$
T_{\text {tip }}=-\frac{0.079 \mathrm{~N} \rho \mathrm{W} v_{0}^{2} \frac{r_{t}^{3}}{b^{2}} t \tan ^{2} \theta_{b}}{2\left[\frac{\rho v_{0}(B-h)}{\mu}\right]^{0.25}\left[\frac{r_{t}\left(B-r_{t}\right)}{b(B-h)} \cdot \tan \theta_{b}\right]^{0.25} \sin \theta_{t}} .
$$

Forming the ratio of Equation (23) to Equation (20):

$$
\frac{T_{t i p}}{T_{v}}=\frac{r_{t}^{3} t \tan ^{2} \theta_{b}}{b^{2}\left[\frac{r_{t}\left(B-r_{t}\right)}{b(B-h)} \tan _{b}\right]^{0.25}\left(r_{t}^{2}-h^{2}\right) \sin \theta_{t}} .
$$

For a flow technology 2 to $20 \mathrm{gpm}$ turbine [Model FT-12M20-LJ(S)] with $\mathrm{B}=0.405$ in, $r_{t}=0.395$ in., $h=0.188$ in., $t=0.020$ in., $b=\sqrt{h \times r_{t}}=0.272$ in., $\theta_{b}=24^{\circ} / 57.3$ radians, the $\mathrm{T}_{\mathrm{tip}} / \mathrm{T}_{\mathrm{v}}$ ratio is

$$
\frac{T_{\text {tip }}}{T_{v}}=\frac{0.0616 \times 0.020 \times(0.445)^{2}}{0.074(0.0298)^{0.25} \times 0.1207 \times 0.41}=0.16 .
$$

The tip retarding torque is consequently only about $16 \%$ of the value of the blade, skin-friction retarding torque for the FT-12M20-LJ(S) turbine.

For the 1 to $13 \mathrm{gpm}$ FT-10S13-LJ(S) turbine $B=0.251$ in., $r_{t}=0.243 \mathrm{in}$, $\mathrm{h}=0.115$ in., $\mathrm{t}=0.020$ in., $\mathrm{b}=0.167$ in., $\theta_{\mathrm{b}}=40 / 57.3$ radians, or

$$
\frac{T_{\text {tip }}}{T_{v}}=\frac{0.0143 \times 0.020 \times(0.839)^{2}}{0.028 \times(0.0718)^{0.25} \times 0.0458 \times 0.642}=0.47
$$

Thus, in the smaller of the two turbines, the tip retarding torque is about $50 \%$ of the blade fluid friction retarding torque. It can be concluded that blade tip drag is not the most significant of viscous effects. The ratios obtained here will be used in Section I-5 in obtaining a total fluid retarding torque for studying the slip caused by fluid drag.

\subsection{Bearing Viscosity Retarding Torque}

Lightly loaded ball bearings and journal bearings behave differently from one another particularly in operation at low rpm. The lightly loaded ball bearing requires no minimum rotational rate to achieve minimum friction, whereas the journal bearing does. Lightly 
loaded and turning above some minimal rpm, the journal bearing will obey the Petroff Equation of retarding torque ${ }^{[4]}$ :

$$
T_{J B}=\frac{\mu \pi D^{3} L V_{0} \tan \theta_{b}}{2 b C}
$$

where

$$
\begin{aligned}
& \mathrm{D}=\text { shaft diameter } \\
& \mathrm{L}=\text { journal length } \\
& \mathrm{C}=\text { diametrical clearance. }
\end{aligned}
$$

'The other terms have heen defined before. Thic equation considcrs the liglitly luaded shaft to self-center in the bearing which it obviously cannot do below some minimum rpm. Using $\mu=1.75 \times 10^{-5} \mathrm{lb}$ sec/ $/ \mathrm{ft}^{2}, \quad D=0.125 / 12 . \mathrm{ft}, \quad \mathrm{L}=0.5 / 12, \quad V_{\mathrm{o}}=1.6 \mathrm{ft} / \mathrm{scc}, \theta_{\mathrm{b}}=24^{\circ}$, $\mathrm{b}=0.2^{\prime} 72 / 12 \mathrm{ll}$ and $\mathrm{C}=0.001 / 12 \mathrm{ft}, \mathrm{T}_{\mathrm{JB}}=-4.88 \times 10^{-7} \mathrm{lb} \mathrm{ft}$. Because Equation (20) for the retarding torque due to blade skin friction gives $\mathrm{T}_{\mathrm{V}}=-2.91 \times 10^{-6} \mathrm{lb} \mathrm{ft}$, the bearing torque is thus not significant so long as the Petroff Equation holds. However at some low-end rpm, shaft-to-bearing contact will start to occur and the bearing torque will increase significantly.

\section{CALIBRATION WITH FLUID RETARDING TORQUES}

With no retarding torque, Equation (11) gives

$$
\ddot{\theta}_{0}=\frac{\tan \dot{\theta}_{b}}{b} \frac{\int_{h}^{r} v^{2}(r) r^{2} d r}{\int_{h}^{r} t \ln (r) r^{2} d r} .
$$

Selecting arbitrarily the total retarding torque to be $1.5 \mathrm{~T}_{\mathrm{v}}$ to cover the effects of blade skin friction, blade tip, and other retarding torques as covered in Sections $\mathrm{I}-4.2$ and -4.3 , at equilibrium the sum of the torques is zero:

$$
\begin{aligned}
T_{d}+1.5 T_{v}=0 & =N \rho W\left(\frac{\tan \theta_{b}}{b} \int_{h}^{r t} v^{2}(r) r^{2}\left[1-\frac{\dot{\theta}_{v} b}{V(r) \tan \theta_{b}}\right] d r\right. \\
& \left.-\frac{0.06 v_{0}^{-2}\left(r_{t}^{2}-h^{2}\right)}{(\operatorname{Re})^{0.25}}\right\}
\end{aligned}
$$


or

$$
\dot{\theta}_{v}=\frac{\frac{\tan \theta_{b}}{b} \int_{h}^{r} v^{2}(r) r^{2} d r-\frac{0.06 v_{0}^{2}\left(r_{t}{ }^{2}-h^{2}\right)}{(\operatorname{Re})^{0.25}}}{\int_{h}^{r_{t}} v(r) r^{2} d r} .
$$

Then:

$$
\begin{aligned}
& \text { STip }=\frac{\dot{\phi}_{0}-\dot{\theta}_{v}}{\emptyset_{0}}=\frac{0.06 v_{0}{ }^{2}\left(r_{t}{ }^{2}-h^{2}\right) b}{(\operatorname{Re})^{0.25} \tan \theta_{b} \int_{h}^{r} v^{2}(r) r^{2} d r} \\
& =\frac{0.06\left(r_{t}^{2}-h^{2}\right) b}{(R e)^{0.25} \tan \theta_{b} \int_{h}^{r}\left[\frac{V(r)}{V_{0}}\right]^{2} r^{2} d r} .
\end{aligned}
$$

Similarly to Equation (20), it is now assumed $V(r)=V_{0}$ and that an approximate expression for the slip becomes

$$
\text { Slip } \approx \frac{0.18 b\left(r_{t}^{2}-h^{2}\right)}{(\operatorname{Re})^{0.25} \tan _{b}\left(r_{t}{ }^{3}-h^{3}\right)}
$$

For the FT-12M20-LJ(S) 0.810-in.-diameter bore, 2 to 20 gpm turbines:

$$
\text { S1ip to } 20=\frac{0.24}{(\operatorname{Re})^{0.25}}
$$

where

$$
\operatorname{Re}=\frac{\rho V_{0}^{\cdot}(B-h)}{\mu}
$$


and

$$
v_{0}=\frac{f t^{3} / \mathrm{sec}}{f t^{2}}=\frac{\frac{g p m}{448.83}}{\frac{\pi\left(B^{2}-h^{2}\right)}{144}}=0.794 \times(\mathrm{gpm}) \mathrm{ft} / \mathrm{sec}
$$

giving

$$
\begin{array}{ccc}
\text { Slip }=3 \%, & \text { Slip }=1 \%, & \text { and Slip }=2 \% \\
2 \text { gpm } & 20 \text { gpm } & \text { cold } \\
\text { cold } & \text { water } & \text { gpm } \\
\text { water } & \text { water } & \text { water }
\end{array}
$$

where $\quad \rho_{\substack{\text { cold } \\ \text { water }}}=\frac{67.4}{32.2} \frac{\mathrm{slug}}{\mathrm{ft}^{3}}, \dot{\rho}_{\text {hot }}=\frac{47}{32.2} \frac{\mathrm{slug}}{\mathrm{ft}^{3}}$

and

$$
\underset{\substack{\text { cold } \\ \text { water }}}{\mu}=1.75 \times 10^{-5} \mathrm{lb} \mathrm{sec} / \mathrm{ft}^{2} \text { and } \mu_{\substack{625^{\circ} \mathrm{F} \\ \text { water }}}=1.75 \times 10^{-6} \mathrm{lb} \mathrm{sec} / \mathrm{ft}^{2}
$$

have been used to evaluate these slips.

For the FT-10S13-LJ(S) 1 to 13 gpm turbine:

where

$$
\operatorname{sip}_{1 \text { to } 13}=\frac{0.13}{(\operatorname{Re})^{0.25}}
$$

$$
\operatorname{Re}=\frac{\mu V_{0}(B-h)}{\mu}
$$

and

$$
\begin{array}{lrl}
V_{0}-2.05 \times(\mathrm{gpm}) \mathrm{ft} / \mathrm{sec}, & \text { giving } \\
\text { S1 ip }=2 \%, & \text { S1 ip }=0.5 \%, & \text { and } \mathrm{s} 1 \mathrm{ip}=1 \% \\
1 \mathrm{gpm} & 13 \mathrm{gpm} & \mathrm{gpm} \\
\text { cold } & \text { cold } & 625^{\circ} \mathrm{F} \\
\text { water } & \text { water } & \text { water }
\end{array}
$$

Because the calibration constant in pulses/sec/gpm is proportional to (1-slip), one can compare the slip results predicted with the calibration curve obtained experimentally if all variations in the calibration constant are assumed due only to slip. Figure 2 shows the variation of the calibration constant versus flow rate for two different Model FT-12M20-LJ(S) 2 to $20 \mathrm{gpm}$ turbines calibrated using Stoddard Solvent with kinematic viscosity of about 1.5 centistokes. No variation occurs in the graph that can be 


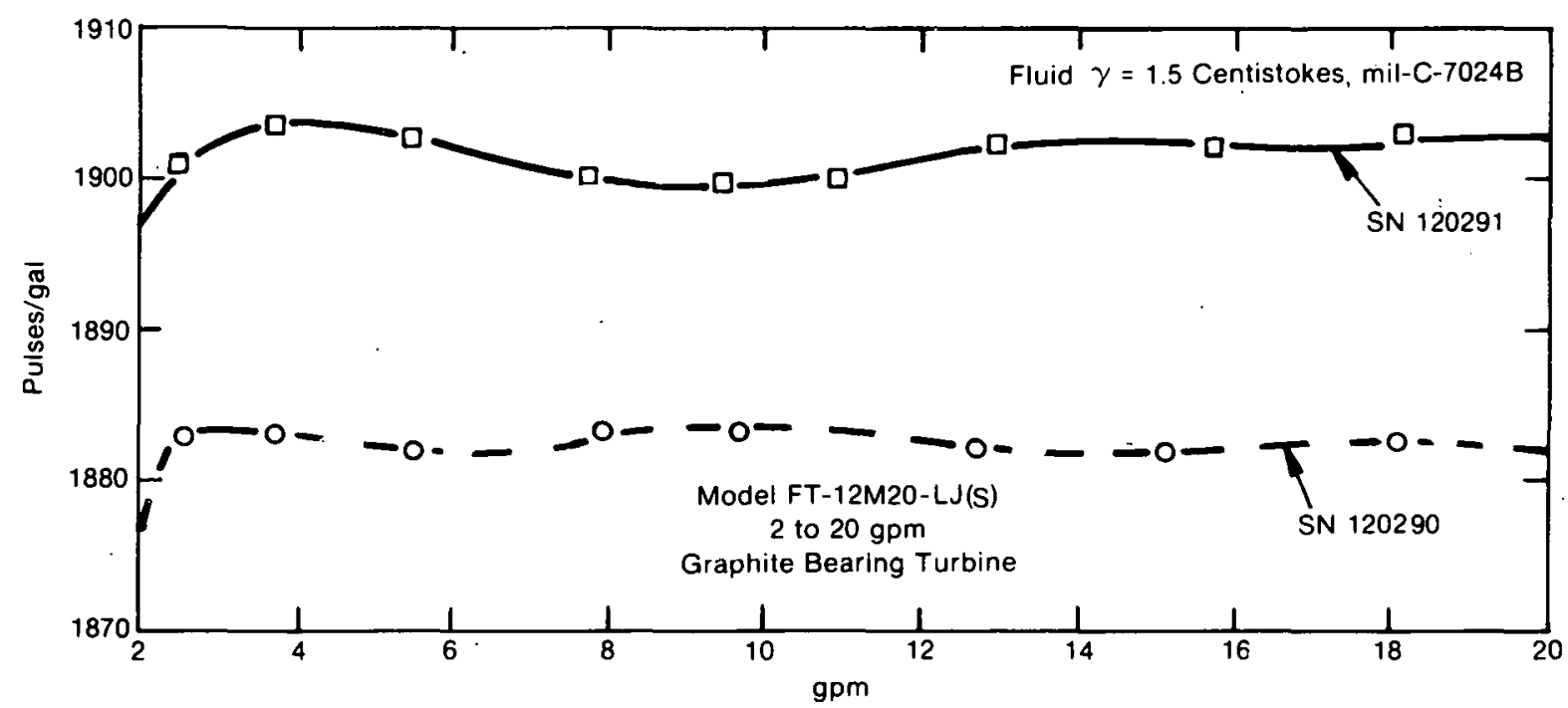

Fig. 2 Calibration constant for 2 to 20 gpm graphite turbines.

interpreted as slip or as a change in slip. The calculations previously performed would have predicted a slip of 3.5 and $1.2 \%$ at 2 and $20 \mathrm{gpm}$, respectively if $\gamma=1.5$ for Stoddard Solvent was used rather than the value of 0.84 centistoke for cold water resulting from using $\mu=1.75 \times 10^{-5} \mathrm{lb} \mathrm{sec} / \mathrm{ft}^{2}$ and $\rho=62.4 / 32.2$. It is thus apparent that the retarding torque coefficient in Equation (32) is too large.

The rapid decline in the calibration constant shown in Figure 2 at $2 \mathrm{gpm}$ and below is not of the form

$$
C=C_{0}\left(1-C_{1} / R e^{0.25}\right)
$$

nor is it of the form

$$
c=c_{0}\left(1-c_{2} / V_{0}\right)
$$

which results if the flow were laminar rather than turbulent. So it is likely due to journal bearing friction rather than fluid retarding torque. It is likely due to the failure of the Petroff Equation to hold, and the journal shaft starting to make contact with the journal bearing, as was discussed in Section I-4.3.

Inspection of Figure 3 shows that the ball bearing turbine also exhibits a decline of the calibration at about $2 \mathrm{gpm}$, but that the rate of decline is significantly less. Because the Reynolds number for Stoddard Solvent at $2 \mathrm{gpm}$ (i.e., $\mathrm{V}_{\mathrm{o}}=1.6 \mathrm{ft} / \mathrm{sec}$ ) is about 1800 , it is likely that a transition from turbulent to laminar flow is occurring [1]. The laminar equivalent of Equation (37) mentioned above is

$$
C=C_{0}\left(1-C_{2} / V_{0}\right)
$$




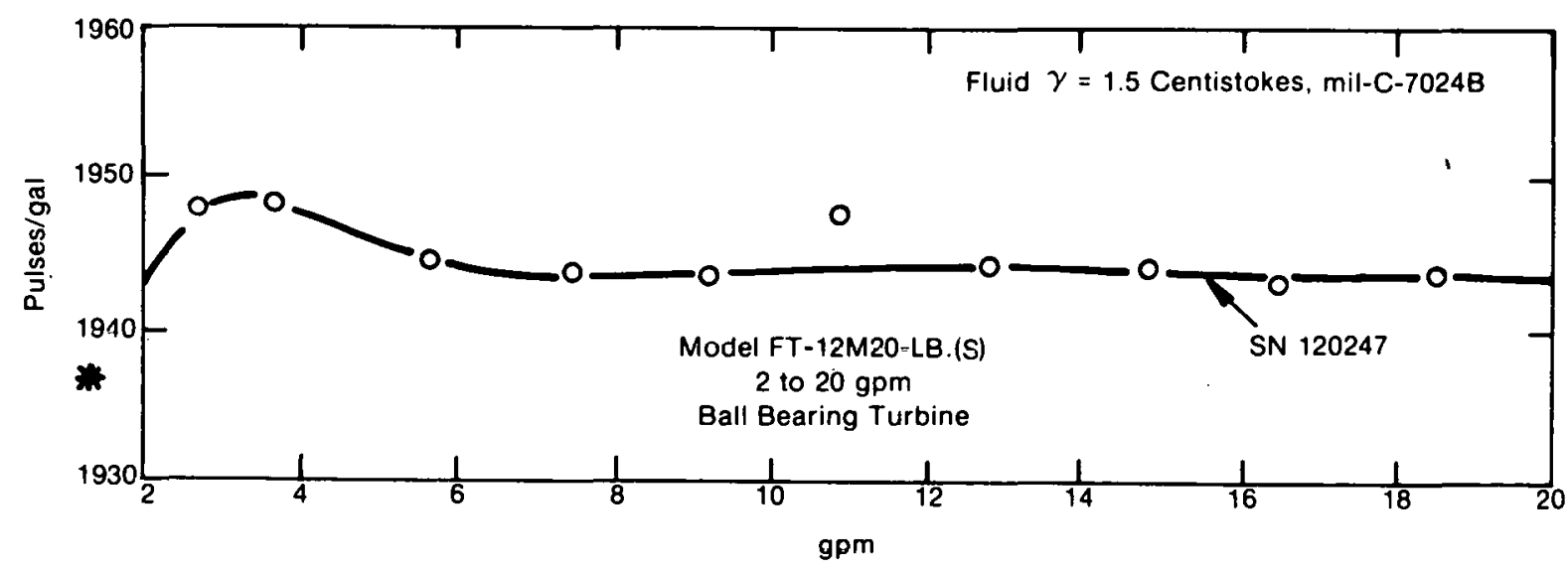

Fig. 3 Calibration constant for 2 to $20 \mathrm{gpm}$ ball beaning tupblno.

Matching the lowest two data points of Figure 3 with Equation (38) gives $\mathrm{C}_{\mathrm{o}}=1963.28$ and $C_{2}=0.0216$, yielding a predicted output at $1.5 \mathrm{gpm}$ of $1935 \mathrm{pulses} / \mathrm{gal}$. This is asterisked in Figure 3 and looks about right.

Figure 4 shows the variation of the calibration constant versus gpm for two 1 to $13 \mathrm{gpm}$ Model FT-10S13-LJ(S) turbines. The Reynolds number for this unit at $1 \mathrm{gpm}$ is 3860 using Stoddard Solvent, $\gamma=1.5$ centistokes.

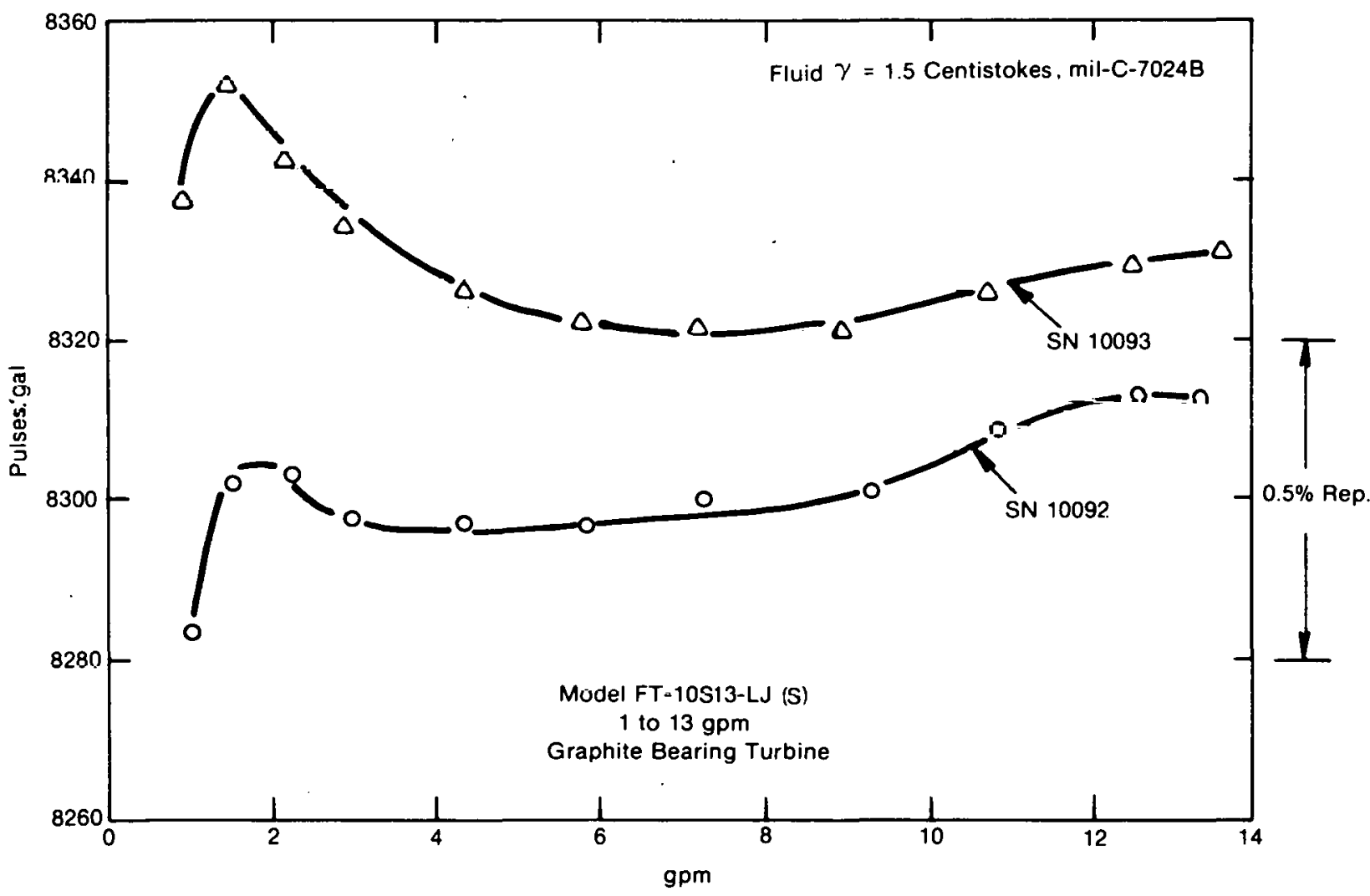

Fig. 4 Calibration constant for 1 to 13 gpm graphite turbines. 
In conclusion of this section, it can be said that for the flow technology Model FT-12M20-LJ(S) or LB(S) types (i.e., 2 to $20 \mathrm{gpm}$ range), fluid retarding torque is not significant above about $3 \mathrm{gpm}$ where turbulent flow occurs. At $3 \mathrm{gpm}$ and below, the flow profile is becoming laminar. In the ball bearing $\mathrm{LB}(\mathrm{S})$ type turbine the $\left(1-\mathrm{C}_{2} / \mathrm{V}\right)$ laminar-slip is evident, but in the $\mathrm{LJ}(\mathrm{S})$ graphite type turbine another effect is predominate. As stated before, this is likely to be due to a rapid increase in journal bearing friction.

\section{FLUID LUBRICITY}

Fluid viscosity and density alone do not under all conditions sufficiently characterize a fluid to completely determine a bearing's behavior. The term "lubricity or oiliness" is used to define an important property of fluids, as used in bearings ${ }^{[4,5]}$. A fluid with good lubricity forms long chain molecules which tend to hold the shaft and bearing apart from one another when the necessary conditions for satisfactory hydrodynamic lubrication involving only $\mu$ become borderline. Also, depending on the respective journal and shaft materials, a particular degree of lubricity may or may not be adequate to keep bearing friction down and to prevent bearing damage. Graphite-to-metal contact is not nearly as detrimental as metal-to-metal contact when a fluid's lubricity is poor. A fluid with long chain molecules, perhaps having good lubricity, may be non-Newtonian in viscous behavior. The fluid would not necessarily follow Equation (38) in the laminar region but probably lie between the predictions of Equations (37) and (38). 


\section{CHANGE IN CALIBRATION DUE TO TEMPERATURE}

\section{GEOMETRICAL}

Due to thermal expansion, the cross-sectional area for flow passage can change with temperature changes. Since the thermal expansion coefficient of metals is rclatively small, this effect clearly cannot be important unless considerable temperature change occurs. An estimate of the size of this effect can be made fairly easily and with much more confidence in the validity of the answer than of the retarding torques, etc., calculated in earlier sections. This is true because the aclual calibiation constant for the two models of turbines is close to constant over their respcctive lluw sanges. This allows the present problem to he treated strictly geometrically for a first-order estimate of the calibration change.

For the definition of $b$ :

$$
\dot{\phi}=\frac{v_{0} \tan \theta_{b}}{b} .
$$

The actual gal/sec passing through the turbine versus the rotor angular veloctty is whid is really of concern:

$$
\mathrm{gal} / \mathrm{sec}=A V_{0} K^{\prime}=\frac{A K^{\prime} \emptyset \mathrm{b}}{\tan \theta_{b}}
$$

or the calibration constant, $C$, is

$$
C=\frac{\mathrm{pu} \text { ses } / \mathrm{sec}}{\mathrm{ga} T / \mathrm{sec}}=\frac{\mathrm{pulses}}{\mathrm{gal}}=\frac{N \frac{\dot{\phi}}{2 \pi} \tan { }_{\mathrm{b}}}{A K^{\prime} \dot{\phi} \mathrm{b}}=\frac{K}{A b}
$$

where $K^{\prime}$ and $K$ are constants:

$$
K=\frac{N \tan \theta_{b}}{2 \pi K^{\prime}}
$$

In Sections I 4.2 and $-4.3, \mathrm{~h}=\sqrt{\mathrm{h} \mathrm{r}_{\mathrm{t}}}$ is used. Here $\mathrm{b}=\sqrt{\mathrm{h} \mathrm{B}}$ shall be used because it leads to a "worst case" variation for $b$. The value of $A$ that will be used is the annular area between the rotor hub and the turbine bore, minus the rotor blade cross-sectional area:

$$
A_{0}=\pi\left(B_{0}^{2}-h_{0}^{2}\right)-N\left(h_{0}-r_{t_{0}}\right) \frac{t_{0}}{\cos \theta_{b}} \quad \text { (ambient) }
$$


using

$$
\begin{aligned}
\mathrm{B} & =\mathrm{b}_{\mathrm{o}}\left(1+\alpha_{\mathrm{B}} \Delta \mathrm{T}\right) \\
\mathrm{h} & =\mathrm{h}_{\mathrm{o}}\left(1+\alpha_{\mathrm{h}} \Delta \mathrm{T}\right) \\
\mathrm{t} & =\mathrm{t}_{\mathrm{o}}\left(1+\alpha_{\mathrm{h}} \Delta \mathrm{T}\right) .
\end{aligned}
$$

Dropping terms squared in $\Delta \mathrm{T}$ :

$$
\begin{aligned}
A=\pi\left[B_{0}^{2}\left(1+2 \alpha_{B} \Delta T\right)-h_{0}^{2}\left(1+2 \alpha_{h} \Delta T\right)\right]-N\left(h_{0}-r_{t_{0}}\right) \frac{t_{0}}{\cos \theta_{b}}\left(1+2 \alpha_{h} \Delta T\right) \\
b=b_{0} \sqrt{\left(1+\alpha_{h} \Delta T\right)\left(1+\alpha_{B} \Delta T\right)} \approx b_{0}\left(1+\frac{\alpha_{h}}{2} \Delta T\right)\left(1+\frac{\alpha_{B}}{2} \Delta T\right) \\
\quad b_{0}\left[1+\frac{\left(\alpha_{h}+\alpha_{B}\right)}{2} \Delta T\right]
\end{aligned}
$$

$\frac{C_{\text {cold }}}{C_{\text {hot }}}=\frac{A_{0} b}{A b_{0}}$

$$
=\frac{\left\{\pi\left[B_{0}^{2}\left(1+2 \alpha_{B} \Delta T\right)-h_{0}^{2}\left(1+2 \alpha_{h} \Delta T\right)\right]-N\left(h_{0}-r_{t_{0}}\right) \frac{t_{0}}{\cos \theta_{b}}\left(1+2 \alpha_{h} \Delta T\right)\right\}\left(1+\frac{{ }^{\alpha} h+{ }^{\alpha} B}{2} \Delta T\right)}{\pi\left(B_{0}^{2}-h_{0}^{2}\right)-N\left(h_{0}-r_{t_{0}}\right) t_{0} / \cos \theta_{b}} .
$$

The FT-12M20-LJ(S) turbine shroud is 304 stainless so $\alpha_{\mathrm{B}}=9.6 \times 10^{-6} /{ }^{\circ} \mathrm{F}$ and the rotor is $430 \mathrm{~F}$ stainless so $\alpha_{\mathrm{h}}=5.8 \times 10^{-6} /{ }^{\circ} \mathrm{F}$. And, as given before, $\mathrm{B}_{\mathrm{O}}=0.405 \mathrm{in}$, $\mathrm{h}_{\mathrm{o}}=0.188$ in., $\mathrm{N}=8, \mathrm{r}_{\mathrm{t}_{\mathrm{n}}}=0.395, \theta_{\mathrm{b}}=24^{\circ}$, and $\mathrm{t}_{\mathrm{o}}=0.020 \mathrm{in} . \mathrm{C}_{\text {cold }} / \mathrm{C}_{\text {hot }}=1.0163$ is calculated when numbers are substituted in Equation (45). So an approximate 1.6\% decrease in the calibration constant is expected hot versus cold for the $575^{\circ} \mathrm{F}$ temperature difference used in the numerical calculation.

For the FT-10S13-LJ(S) turbine, the shroud again is 304 stainless with $\alpha_{\mathrm{B}}=9.6 \times 10^{-6} /{ }^{\circ} \mathrm{F}$ and the rotor is $430 \mathrm{~F}$ stainless with $\alpha_{\mathrm{h}}=5.8 \times 10^{-6} /{ }^{\circ} \mathrm{F} . \mathrm{B}_{\mathrm{O}}=0.251 \mathrm{in}$., $\mathrm{h}_{\mathrm{o}}=0.115$ in., $\mathrm{N}=6, \mathrm{r}_{\mathrm{t}_{\mathrm{o}}}=0.243$ in., $\theta_{\mathrm{b}}=40^{\circ}$, and $\mathrm{t}_{\mathrm{o}}=0.020$-in. These suhstituted into Equation (45) give $\mathrm{C}_{\text {cold }} / \mathrm{C}_{\text {hot }}=1.0160$. Again, an approximate $1.6 \%$ decrease in calibration constant $\left(\frac{\text { pulses }}{\text { gal }}\right)$ is to be expected hot versus cold for a $57.5^{\circ} \mathrm{F}$ temperature difference. 


\section{FLUID PROPERTIES}

Lubricity has been mentioned in Section I- 6 and will not be discussed further except to note that serious bearing problems may result in using ball bearings in high temperature water because hot water has a very poor lubricity.

The absolute viscosity of water decreases a factor of 10 between 75 and $650^{\circ} \mathrm{F}$. Equation (41) states the meter calibration to vary as $1 / \mathrm{A}$. Since conventional boundary layer theory for turbulent flow states that there is a slow flowing laminar region $\delta$ thick on the turbine wall, there might be some concern with the change in $\delta$ with temperature (i.e., viscosity $)^{[6]}$ giving an effective change in flow area $A$. Theuly ${ }^{[3]}$ predicts the boundary layer to be proportional to $\sqrt{\gamma / \mathrm{Vo}}$ or to $1 / \mathrm{Re}^{0.5}$. Evaluation of the proportionality innstant can be avoided in the case of the two turbines of interest by noting that no significant change in the calibration constant results over the cold flow calibration range where $\delta$ changes from $\delta_{\max }$ at minimum llow rate to $\delta_{\min }$ at maximum flow rate. This means that $\mathrm{A}_{\text {eff }}$ cannot be changed significantly by whatever value $\delta$ may have. The value of $\delta_{\max }$ hot will be about the same as $\delta_{\min }$ cold since flow rangc change and the change in $\gamma$ cancel in these cases. Thus, with the assumption that no variation in the calibration constant is evident over the cold flow range, it is safe to assume $A_{\text {eff }}$ will not be changed by changes. in $\boldsymbol{\gamma}$ when the turbine is used at a higher temperature. 


\section{SUMMARY}

In Section I-1, Equation (2) was derived for the deflection angle of fluid caused by a nonzero rotor slip. In Section I-2, this deflection angle was used to obtain the torque imparted to the rotor in terms of the rotor angular velocity and the variation in the fluid axial velocity versus radius [Equation (9)]. In Section I-3, it was shown that if there are no viscous or frictional retarding torques, the meter calibration constant is indeed constant so long as the radial velocity profile does not change versus flowrate.

In Section I-4, an approximate expression of the retarding torque due to fluid viscous behavior on the blade surfaces [Equation (20)] was first derived. This expression assumed turbulent flow and a flat velocity profile of mean value Vo and is quite apt to be a worst case value for the more rigorous expression of Equation (17). Next, it is shown that the blade tip retarding torque is unlikely to be more than $50 \%$ of the viscous friction retarding torque on the blades [Equations (24), (25), and (26)]. Finally, it was shown that so long as journal bearing rpm is adequate to center the lightly loaded shaft, the bearing torque is small compared to either the tip friction or blade viscous friction torques for the two models of turbines being considered.

In Section I-5, the effect of retarding torques on turbine calibration was considered. Equation (31) gives what should be a fairly accurate estimate of the slip if the expression for $\mathrm{C}_{\mathrm{D}}$ in Equation (12) was completely correct. Numerical comparison of predictions of Equation (24) with experimental results show that the theoretically predicted slip is significantly larger than that which actually occurs so that the numerical coefficient of Equation (18) is too large. Finally, comparison of calibration curves of the journal bearing turbines, with those of identical turbines using ball bearings, shows that the departure from a constant calibration at $2 \mathrm{gpm}$ and below is very likely due to journal bearing to shaft contact at low rpm along with the combined effect of the flow becoming laminar since the Reynold's number is only 1800 . The data for the ball bearing turbine of the same model turbine were shown to have the turbine calibration constant dropping off in a manner consistent with laminar flow theory.

In Section II-1, it was shown that a significant change in calibration is likely to occur by simple geometrical size change when the turbine is used at temperatures considerably different from that at which it was calibrated. This effect of larger flow annular area at high temperatures requires a reduction in the turbine output pulses/gal of flow to obtain the proper volumetric flowrate from the turbine pulse rate output. For a $575^{\circ} \mathrm{F}$ temperature change, a probable $1.6 \%$ change in calibration constant is predicted for each of the two sizes of flow technology turbines now in use.

In Section II-2, it was stated that the poor lubricity of water at high temperatures could be a possible source of problems using ball type bearings. It was also argued that if no significant change in the calibration constant is observed over the cold flow calibration range, that boundary layer thicknesses in water applications are thin enough so that any change in the effective flow area caused by them in using the turbine at higher temperature will not significantly affect the meter calibration constant. 


\section{CONCLUSIONS}

The factors that can change a turbine's calibration versus temperature when calibrated in cold water with the intent to actually use the calibration obtained for hot water flow measurements can be summarized in four statements:

(1) Viscous effects are not important hot if they were not important cold (i.e., if the calibration constant remains constant in the cold calibration through al least the upper four-fifths of the cold calibration to lcss thun the percentage that is ropuired, the geometrical area-rorrected calibration will be valid in hot flow).

(2) Due to flow passage area enlargement at elevated temperature, the value of the calibration constant in pulses/gal must be decreased as shown in Section II- 1 . The annular ared contribution is fairly well defined and amounts to $1.2 \%$ of the $1.63 \%$ total correction for a $575^{\circ} \mathrm{F}$ temperature increase with the two turbines considered. The less well defined contribution due to $b$ changing in value amounts to only $0.43 \%$. Estimation of the correction should then be possible to within $0.3 \%$.

(3) Ball bearing turbines should not be used in hot water per the reasons discussed in Sections I- 6 and II-2.

(4) Giapliite juunal bearings should not bo relied upon to give proper corrected flow rate unless operated hot at least 1.5 times the gpm rating that the turbulent to laminar transition hump occurs when calibrated cold. This condition is included to fairly conclusively exclude llie pussiblity that significant bcaring retarding torque might occur due to operating the journal at too low an rpm (see Section 1-4.3). 


\section{REFERENCES}

1. W. O. Stohmeier, "Turbine Flowmeters, Past, Present, and Future," Paper 2-17-207, ISA Symposium on Flow, May 1971, pp 688, 689.

2. R. E. Thompson and J. Grey, "Turbine Flowmeter Performance Model," Journal of Basic Engineering, 92 (1972) p 719.

3. R. B. Bird, W. E. Stewart, E. N. Lightfoot, Transport Phenomena, New York: John Wiley \& Sons, Inc., 1960, pp 187, 610.

4. J. C. Hunsaker and B. G. Rightmire, Engineering Applications of Fluid Mechanics; New York: McGraw-Hill Book Company, Inc., 1947, pp 188, 300, 316.

5. M. R. Shafer, "Performance Characteristics of Turbine Flowmeters," Journal of Basic Engineering, 84 (1962) p 476.

6. J. Grey, "Calibration of Turbine Flowmeters for Cryogenic Operation," ARS Journal, 30 (1960) p 192. 
DISTRIBUTION RECORD FOR TREE-NUREG-1082

Internal Distribution

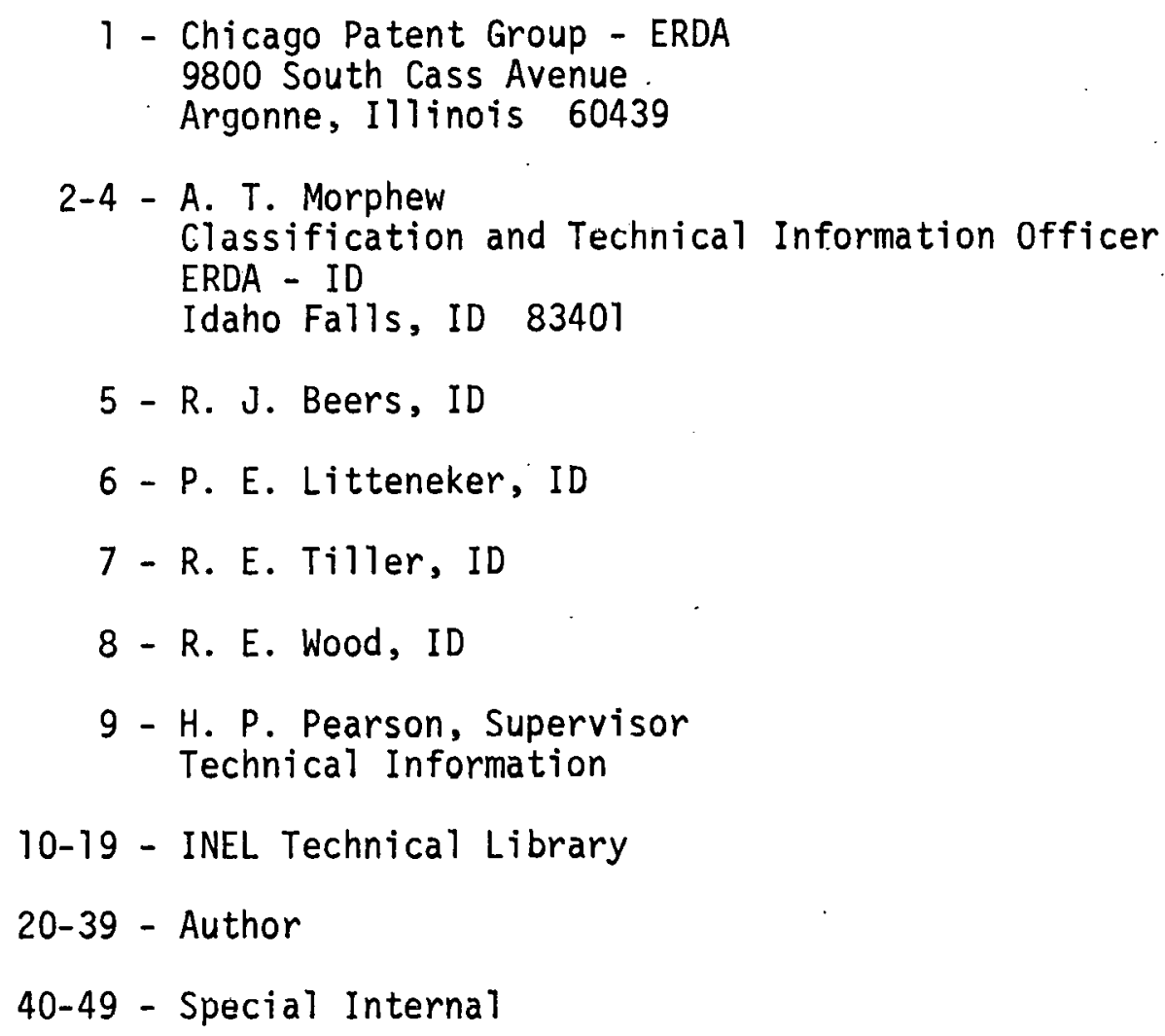

\section{External Distribution}

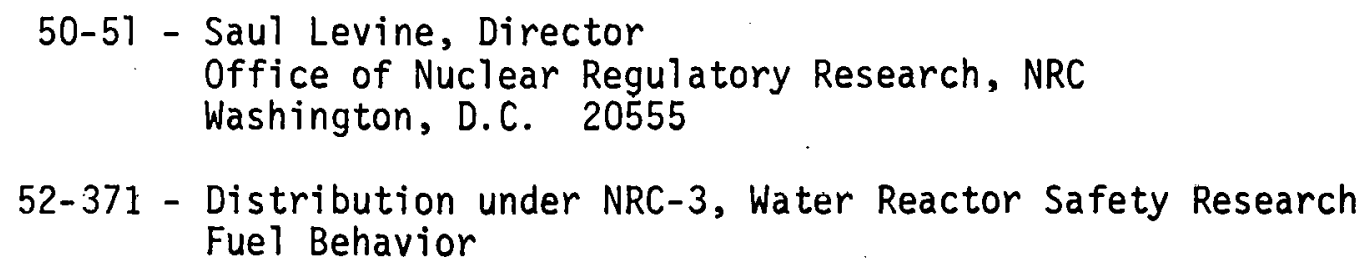

